\title{
Could an Interactive-Balanced Environment for Reading Acquisition Overcome the Triad Risk Factors: Low Socioeconomic Status, Low Literacy Skills and Language Properties?
}

\author{
Baha Makhoul 1,2, Raphiq Ibrahim ${ }^{3,4 *}$ \\ ${ }^{1}$ The NCJW Research Institute for Innovation in Education, The Hebrew University, Jerusalem, Israel \\ ${ }^{2}$ Literacy and Language Arts Department, Center for Educational Technology (CET), Tel-Aviv, Israel \\ ${ }^{3}$ The Edmond J. Safra Brain Research Center for the Study of Learning Disabilities, Faculty of Education, \\ University of Haifa, Haifa, Israel \\ ${ }^{4}$ Department of Learning Disabilities, University of Haifa, Haifa, Israel \\ Email: ${ }^{*}$ raphiq@psy.haifa.ac.il
}

Received 25 October 2014; revised 22 November 2014; accepted 18 December 2014

Copyright (C) 2014 by authors and Scientific Research Publishing Inc.

This work is licensed under the Creative Commons Attribution International License (CC BY).

http://creativecommons.org/licenses/by/4.0/

(c) (i) Open Access

\begin{abstract}
A large number of the scientific efforts that have investigated the issue of Arabic language acquisition have mainly focused on the implication of its Diglossic nature and orthographic complexity in reading acquisition. However, the interplay of the two factors and low-socio economic background was not addressed sufficiently. The current study follows the progress in literacy skills among atlinguistic risk Arabic native speaking kindergarten children throughout 2nd grade, and assesses its impact on reading and writing acquisition in a Diglossic context. Twenty-five at literacy risk children and 181 heterogeneous children (resembling the heterogeneity of Socioeconomic Status (SES) and literacy background in regular classes) took part in the study. The effects of an interactive-balanced reading and writing learning program were evaluated. Children were assessed both at the end of kindergarten and at the beginning of 2 nd grade in the following domains: discourse, listening comprehension, phonology, morphology, syntax and vocabulary. In the post-test, reading measures were included. The results of the study indicate that the learning program succeeded in bridging the gaps in literacy skills between the at-risk children and their heterogeneous peers. However, lower performance was observed in reading measures among the former.
\end{abstract}

\footnotetext{
"Corresponding author.
} 


\section{Keywords}

\section{Arabic, Reading Acquisition, Kindergarten, Literacy, Phonology, Morphology, Vocabulary, Syntax}

\section{Introduction}

For most people, literacy development is an intuitive process that commences in early childhood, while relying mainly on one's exposure to language. However, when socio-economic factors adjoin Arabic Diglossic circumstances and its orthographic complexity, the development of emergent literacy skills is obstructed, affecting later reading and writing acquisition and academic success (e.g. Abu-Rabia, 2000; Hussien, 2014a, 2014b; Lundberg, Larsman, \& Strid, 2012; Makoul, 2006; Morgan, Farkas, Hillemeier, \& Maczuga, 2009; Saiegh-Haddad, 2003, 2004). Cunningham \& Stanovich (1997) have documented the long-term implications of reading acquisition difficulties where reading performance in first grade correlated with reading comprehension, vocabulary and general knowledge in 10th grade. Accordingly, the current study attempts to investigate the impact of the interplay between Arabic linguistic features and low SES background on literacy skills and later on reading acquisition.

\subsection{Reading and Writing Acquisition}

\subsubsection{The Effect of the Unique Features of Arabic on Reading and Writing Acquisition}

Arabic is characterized by its Diglossic nature, which is reflected in the linguistic discrepancy between its spoken and literary standard Arabic form, which have impact on reading and writing acquisition (Ayari, 1996; Khamis-Dakwar \& Froud, 2007; Ibrahim, 2009; Saiegh-Haddad, 2003, 2005). Furthermore, recent scientific evidence suggests that Modern Standard Arabic (MSA) functions as a second language where explicit and intensive exposure to its features occurs only upon commencing formal schooling (Eviatar \& Ibrahim, 2001; Ibrahim \& Aharon-Peretz, 2005; Saiegh-Haddad, 2008). Hence, during scholastic activities, Arab students are confronted with texts that might have been represented differently, if presented in the colloquial variation of Arabic (Khamis-Dakwar \& Makhoul, 2014; Salami, Ibrahim, \& Shany, Submitted).

\subsubsection{The Role of Phonology in Reading and Writing Acquisition}

Intensive and continuous research has established the indispensability of phonological awareness to reading and writing acquisition across different languages (e.g. Castles \& Coltheart, 2004; Caravolas, Volín, \& Hulme, 2005; Hanley, 2005; McBride-Chang et al., 2005; Ziegler et al., 2010; for full review, see: National Institute for Literacy, 2008).

In the case of Arabic, the phonological characteristics of the language impose special practices when teaching the Arabic alphabet to children, following their corresponding manner of articulation (Makhoul \& Iskandar, 2010; Saiegh-Haddad, 2008):

1) Fricatives: The letters (/f/, // ز، س، ش، غ، ف:s/,/Š/, /s/, /z/) are initially taught since they follow similar and distinguishable pattern, facilitating letter-sound correspondence mastery.

2) Plosives: (/q/, /S/, /ḍ/, /ț/) represent phonemes that are hard to pronounce as independent units where children tend to pronounce them as syllabic units, combined with the phoneme /a/ (e.g. /ta/).

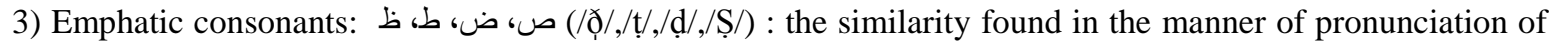
each pair may affect children's phonemic discrimination and consequently, their ability of establishing adequate grapheme-phoneme correspondence.

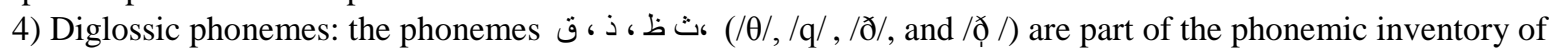
written Arabic (MSA) but not of SA (Maamouri, 1986).

\subsubsection{The Orthographic Features of Arabic}

The complexity of Arabic orthography contributes to the difficulty experienced in reading and writing acquisition. Arabic includes 29 consonants and six vowels (both short and long vowels) (Mahfoudhi, Everatt, \& Elbeheri, 2011; Saiegh-Haddad \& Henkin-Roitfarb, 2014). In contrary to long vowels (high front /i:/, high back /u:/, and low /a:/), short vowels (fatha, Kasra and damma) are denoted by diacritical marks that are usually omitted in written texts, affecting grapheme-correspondence. The inclusion of other misrepresented diacritics such as the 
Šadda (indicating gemination) and tanwin in Arabic script adds to its complexity. While vowelized Arabic is considered shallow orthography, unvowlized Arabic is opaque, and it is intended for skilled readers (Mahfoudhi, Everatt, \& Elbeheri, 2011).

Arabic script is cursive (e.g. bird is written عصفور) where visual similarity is found between some of the let-

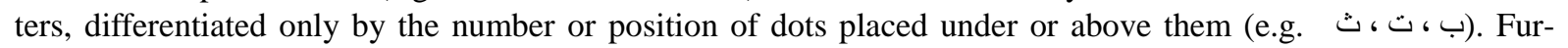
thermore, out of 28 letters, 22 letters have four shape forms which alternate with adequacy to their position in a word: Initial (ب), middle (ب), Final (ب) and separate (ب) forms) Abd El-Minem, 1987). The six remaining letters have only two variations: separate and final.

Accordingly, different scientific efforts have addressed the impact of the visual characteristics of Arabic orthography on reading acquisition. Eviatar, Ibrahim and Ganayim (2004) indicated that the identification of visually similar letters occurs much slowly. In addition, the perceptual load of Arabic orthography was correlated with processing difficulties in reading Arabic where visual short-term memory accounted for the differences between skilled and poor readers (Abu-Rabia, Share, \& Mansour, 2003; Abdelhadi, Ibrahim, \& Eviatar, 2011; Ibrahim, Eviatar, \& Aharon-Peretz, 2002). Mohamed, Elbert and Landler (2011) suggested that visual and spatial abilities have potential role in reading fluency, especially in early stages of acquisition.

\subsection{Socio-Economic Background and Emergent Literacy Skills: The Route to Reading Acquisition}

Upon commencing first grade, children are highly motivated and excited to pursue their scholastic education, but are soon challenged by the turbulent journey towards literacy acquisition, already starting from early childhood and manifested differently in its manner of occurrence and pace. Different factors operating simultaneously in the child's surroundings influence emergent literacy skills and subsequent reading acquisition, such as socio-economic background, language and meta-linguistic skills development (Pianta \& Cox, 1999; Ramey \& Ramey, 1999). These factors amplify the difficulties experienced by Arab first-graders during the significant transitional phase, while confronted with the challenge of acquiring reading and writing in a markedly discrepant variation of their native spoken language.

Emergent literacy skills are the building blocks of reading development, predicting children's reading skills in elementary school (e.g. Aram, Korat, \& Hassunah-Arafat (2013); Cabell, Justice, Konold, \& McGinty, 2011; Lonigan, Burgess, \& Anthony, 2000; Mol, \& Bus, 2011). Socio-economic status has been found to impact children's cognitive development, especially language functions (Hackman, Farah, \& Meaney, 2010; Jednoróg, Altarelli, Monzalvo, Fluss, Dubois et al., 2012). Many studies have pointed out the relationship between early literacy skills and academic success, indicating a significantly lower academic performance when comparing groups from low SES to their counterparts from more advantageous socio-economic backgrounds (e.g. Aikens \& Barbarin, 2008; Lundberg, Larsman, \& Strid, 2012; Morgan, Farkas, Hillemeier, \& Maczuga, 2009, 2012). Such a discrepancy is already apparent in early stages; children from low SES begin formal schooling with lower meta-linguistic skills and limited exposure to literacy fostering environments and thus considered to be at-risk for reading difficulties (Lundberg, Larsman, \& Strid, 2012). Specifically, Makhoul (2006) and Makhoul \& Ibra-him (2012) stressed the necessity of mastering the required phonological and oral language skills in Arabic reading and writing acquisition, pointing out the importance of early exposure to literacy activities and enhancing children's interest, enjoyment, and motivation in reading activities.

The interaction of Arabic socio-linguistic context with environmental risk factors such as low SES hampers adequate reading acquisition. Data collected for international literacy tests, such as PIRLS (2006), showed that Arab native speakers have poor achievement in reading. In Israel, the reading scores of Arabic-speaking fourthgrade students were significantly lower than their Hebrew-speaking peers, stemming both from the Arabic Diglossic nature and the socioeconomic inequality between these two sectors (Zuzovsky, 2010). Thus, a multicomponential compensating approach is required.

\subsection{The Current Study}

The aim of the current study is to investigate the conjoint effect of the Arabic Diglossic nature, its orthographic characteristics and low SES on literacy skills and reading acquisition. Specifically, we assessed the effect of promoting literacy knowledge on later reading skills among low SES at-risk children, while following their progress from kindergarten throughout second-grade. The children were assessed for their discourse and listen- 
ing comprehension skills, morphological, phonological, syntactic and vocabulary knowledge, both before the program commencement and after its termination. In addition, reading assessment (technical and reading comprehension) was included in the post-test.

Accordingly, the current study attempted to investigate the following questions:

1) Will at-linguistic risk preschool children demonstrate an initial lag in literacy skills (phonology, discourse, listening comprehension, morphology, syntax, and vocabulary) when compared to their heterogeneous classmates?

2) How will an interactive-balanced learning program benefit literacy domains in each group?

3) How will multi-dimensional literacy promoting program affect later reading performance and comprehension?

4) Is there a relationship between the assessed literacy skills after working in the learning program and reading performance in both groups?

\section{Method}

\subsection{Participants}

206 Arabic native speaking children from five different Arab northern schools in Israel were selected to participate in this study. One school was considered as a low SES school; its target population arrives mainly with low literacy skills and limited exposure to written language. In the low SES school, 25 children were assigned to atlinguistic Risk group (LR), whereas the other 181 children (from the other four schools) were assigned to the Heterogeneous Group (HG), resembling the heterogeneity in SES and literacy skills in a regular class. Children with neurological disorders, learning disabilities, and emotional difficulties were excluded from the study (Table 1).

\subsection{Measures}

A literacy assessment battery was devised and validated (Makhoul, 2006; Makhoul \& Ibrahim, 2012) which included: discourse, listening comprehension, phonological awareness, vocabulary, and reading measures. The testers documented children's answers and responses. The measures are described in Table 2.

\subsection{Procedure}

\subsubsection{Reading Literacy Program-“Arabic Is Our Language"}

Upon commencing first grade, all the children participated in "Arabic is our Language" reading program, which was based on the interactive model for reading and writing acquisition (Adams, 1991), taking into account the role of its four processors: context, phonology, orthography and semantics and that was adapted to the new curriculum of Arabic Language (State of Israeli Ministry of Education, 2009). The program development was carried out by the team of the Arabic Language Department at the Center for Educational Technology (CET) (Makhoul, Iskandar, Ibrahim, \& Hijazi, 2010).

The instructional format of the program included two stages, emphasizing a direct instructional approach that sets grounds for developing reading automaticity to ultimately derived meaning. At the first stage, the program focuses on fostering phonological awareness, orthographic knowledge, decoding skills, listening comprehension, and discourse. The second stage focuses on developing reading skills fluency of short texts, without reliance on context, while promoting comprehension skills and listening comprehension, besides to acquisition of appropriate spoken conversation and linguistic knowledge.

The program takes into account both the cognitive and developmental aspects of reading acquisition, and

$$
\text { Table 1. Distribution of children in study groups. }
$$

\begin{tabular}{cccc}
\hline Group & Males & Females & Total \\
HG & 77 & 107 & 184 \\
LR & 13 & 12 & 25 \\
Total & 90 & 119 & 206 \\
\hline
\end{tabular}


Table 2. Literacy measures by domain ${ }^{1}$.

Discourse Skills Measure (DSM) (Makhoul \& Ibrahim, 2012)

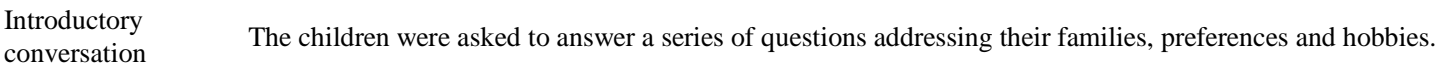

Picture description The children were presented with a picture and were asked to describe it.

Storytelling The children were required to tell a story, following the presented picture.

Listening Comprehension Measure (LCM) (Makhoul \& Ibrahim, 2012)

After listening to a story twice, a story recall-task was followed (Short-Term Recall)

Story Then, they were asked to answer orally a series of comprehension questions and were ultimately asked to recall

comprehension the story after 20 min delay (Long-Term Recall).

The story recall and answers were assessed by indices of Makhoul (2006).

Instructions' Nine items were included in this task, requesting the children to follow the tester’s instructions. For example:

comprehension “draw a kite above the longer pen”.

Sentence-picture The children were required to choose the sentence that best describes the presented picture matching (out of five sentences read by the tester).

Arabic Phonological Awareness Measure (APAM) (Makhoul \& Ibrahim, 2012)

All the used tasks were adapted to Arabic based on the Reading Readiness Screening Tool (RRST) developed by Learning Disabilities Association of Alberta (2009).

Auditory Word detection

Syllable Detection

Phoneme detection

Five sentences were presented. The children were asked to count the number of the heard words following each sentence by using their finger.

The children were asked to map the number of syllables appearing in a heard word by "clapping” each syllable out.

The children were asked to sound the heard phonemes in the presented words. Due to their insufficient sensitivity to short vowels when blended with consonant sounds, they were only evaluated for their capacity to map consonant sounds.

For example, the word “كَتَبَ" (/kataba/) consists of 3 consonants and 3 short vowels (/a/) represented by the diacritical mark fatha $(二)$

Rhyme generation The task requires generating a rhyming word with previously sounded target words or pseudo-words.

Standard Arabic Morphological Awareness (SAMA) Adapted and revised from Abu-Ahmed (2008)

Morphological awareness
The task assesses awareness to word morphological structure in written Arabic. Each item includes a pair of real and pseudo words, allowing assessment of the different aspects of inflectional structures in Arabic (gender, tense, number, person and mood). The children are asked to select the word with the corresponding morphological structure.

Test of Receptive Oral Grammar Adapted to Modern Standard Arabic from Bishop (1994)

T.R.O.G

The children were presented with four pictures and were asked to select the picture corresponding to the heard word or sentence. The test includes 20 syntactic categories (e.g. negative form, adjectives, comparison forms, passive forms...).

Arabic Vocabulary Measure (AVM) (Makhoul \& Ibrahim, 2012)

Expressive

Vocabulary

Generalization

Odd Word Out

Story Sequencing
The test consists of two parts. The first part includes 15 items, requiring the children to name the presented pictures. In the second part, the children are asked to point to the picture that corresponds to the heard word.

The children were asked to draw a line between each pair belonging to the same category.

Four pictures were presented and the children were instructed to draw a circle around the picture that doesn't belong and to justify their answer.

The children were presented with 4 pictures and were asked to sequence the pictures in the correct order, to create a story and tell it. 


\section{Continued}

Arabic Reading and Comprehension Measure (ARCM)

Pseudo-word reading

(Abu-Ahmed, 2008) To assess decoding skills, six items are introduced, including one exemplary item.

Context-free Oral The children were asked to read five familiar words that they have previously been exposed to during the program. Word Naming In addition, the children were presented with another five unfamiliar words (context free).

The children were asked to read a short passage (51 words). They were
Text Reading and $\quad$ correct read words) and Fluency-Rate (Time of reading in seconds).

Comprehension In addition, they were asked to retell the story and to answer a set of questions dealing with the read story (their performance was assessed by Makhoul gauges (2006)).

${ }^{1}$ The tools were briefly discussed due to their large amount; if necessary, we could add them as an appendix.

draws on previous scientific data addressing reading acquisition in Arabic (Makhoul, 2006; Makhoul \& Ibrahim, 2012; Makhoul, Olshtein, \& Ibrahim, 2013) (See Figure 1).

\subsubsection{Assessment Procedure}

The first assessment was held during May-June 2011, at the end of kindergarten year whereas the second assessment was held at the start of second-grade during September-October 2012. In both assessments, the literacy battery test was administered by qualified testers for 45 minutes. Furthermore, in the post-test, the children's reading skills were assessed (technical reading and reading comprehension).

\subsection{Statistical Analysis}

An overall mean score was calculated for each domain, on pre-test and post-test. Paired-samples t-test was conducted to assess the children's progress over the program period. An independent-sample t-test was carried out to compare literacy knowledge and reading skills between the HG and LR groups, both in the pre-test and posttest. In addition, effect sizes were calculated where $0.20,0.50$ and 0.80 are considered weak, moderate and strong, respectively (Cohen, 1977; Rosenthal \& Rosnow, 1984).

A series of multiple linear regression analyses were conducted in order to reveal the effects of the six domains in the learning program on reading accuracy and reading comprehension.

Ultimately, Pearson correlation coefficients were calculated to assess the relationship between the different literacy skills and reading. Furthermore, Simple Interactive Statistical Analysis (SISA) was calculated to assess whether differences were found in Pearson correlations between HG and LR.

\section{Results}

\subsection{Initial Differences in Literacy Skills between LR and HG in Preschool}

For the pre-test, an independent-sample t-test was performed to assess the initial difference in literacy skills among HG and LR groups (kindergarten, end of year). The differences in mean scores in the various literacy domains are presented in Figure 2.

As seen in Figure 1, HG groups demonstrated significantly higher initial performance in listening comprehension $(t(204)=2.69, p<0.01)$, phonology $(t(204)=4.37, p<0.001)$, syntax $(t(204)=2.51, p<0.05)$ and morphology $(t(204)=2.84, p<0.01)$. In addition, Cohen's effect size value suggests large effect for discourse skills $(E S=0.68)$ while low effects were obtained for listening comprehension $(E S=1.8)$, phonology $(E S=$ $0.05)$, morphology $(E S=0.10)$, syntax $(E S=0.26)$ and vocabulary $(E S=0.14)$.

Pre-test results indicated an initial gap between the two groups; higher literacy knowledge was observed in the HG when compared to LR.

\subsection{The Efficacy of "Arabic Is Our Language" in Bridging the Gaps between LR and HG Groups in the Different Literacy Domains}

In the post-test assessment, no significant difference was found in literacy skills between LR and HG groups, except in vocabulary $(t(204)=2.89, p<0.01)$ (see Figure 3 ). 


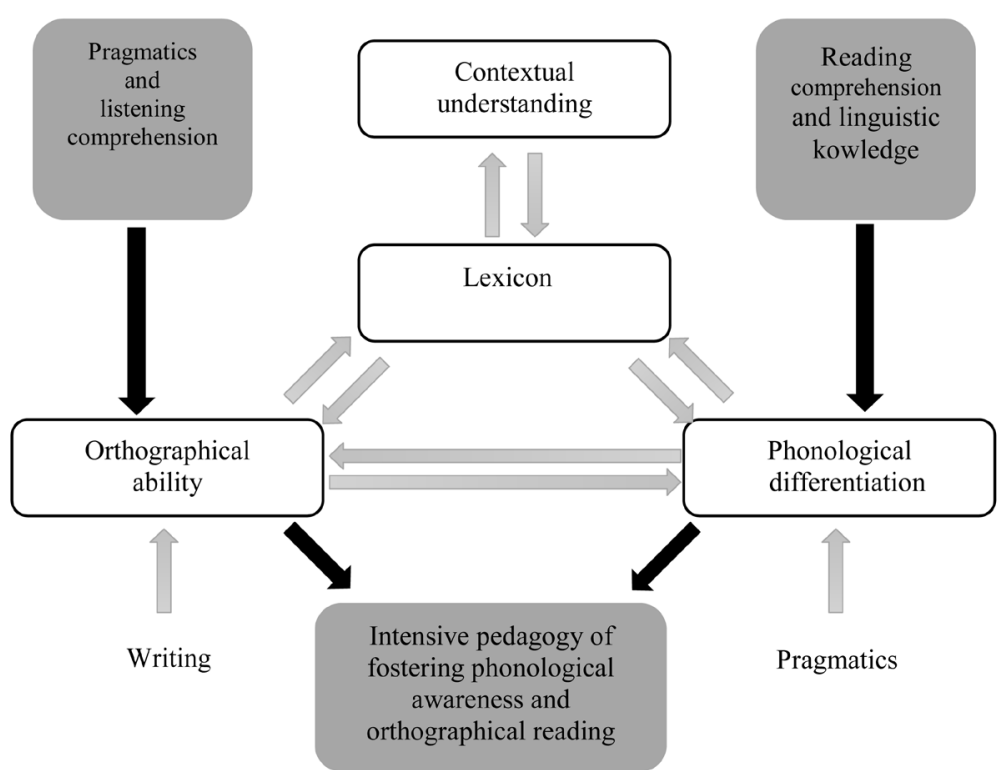

Figure 1. Cognitive and developmental aspects in Arabic reading acquisition.

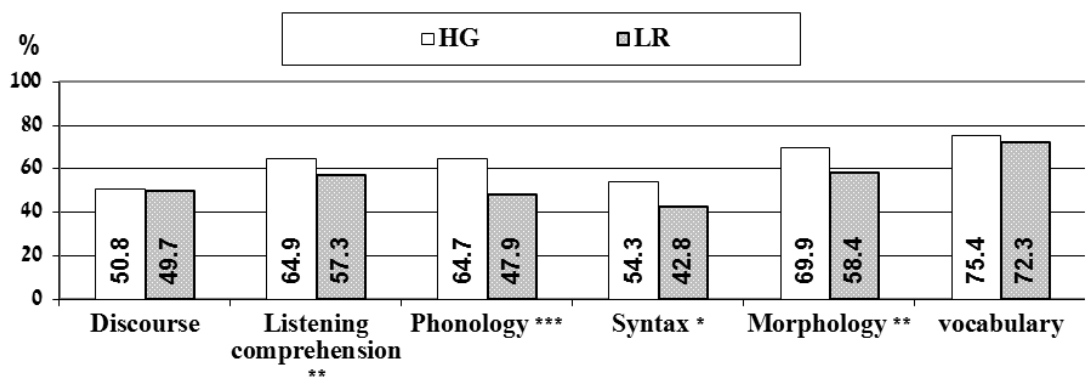

${ }^{*} p<0.05 ;{ }^{* *} p<0.01 ;{ }^{* * *} p<0.001$.

Figure 2. Differences in literacy mean scores among HG and LR group in kindergarten-Pre-test (end of year).

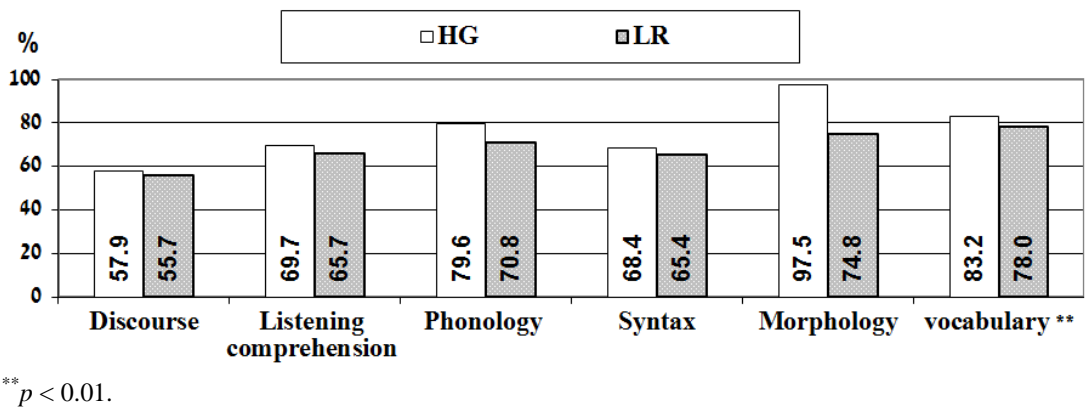

Figure 3. Differences in literacy mean scores between HG and LR group-Post-test (after learning in the program).

This Post-test results showed the efficacy of "Arabic is our Language" program in promoting literacy skills and closing the gaps between the LR and HG groups, except in vocabulary knowledge.

\subsection{The Efficacy of "Arabic Is Our Language" in Promoting Literacy Knowledge in Each Group}

In the HG group, significant progress was found in all literacy measures: discourse $(t(180)=6.82, p<0.001)$, 
listening comprehension $(t(180)=5.04, p<0.001)$, phonology $(t(180)=11.72, p<0.001)$, syntax $(t(180)=$ $10.35, p<0.001)$, morphology $(t(180)=0.73, p<0.001)$ and vocabulary $(t(180)=10.56, p<0.001)$ (see Figure 4).

Similarly, after participating in the program, the LR group showed a higher performance in listening comprehension $(t(24)=3.22, p<0.001)$, phonology $(t(24)=7.10, p<0.001)$, syntax $(t(24)=5.55, p<0.001)$, morphology $(t(24)=3.28, p<0.01)$ and vocabulary $(t(24)=2.69, p<0.05)$. In contrast, no significant improvement was observed in discourse skills after working in the program $(M=49.68, S D=12.34)$ when compared to pretest assessment $(M=55.67, S D=11.52)$ (See Figure 5).

\subsection{The Effect of Literacy Skills on Reading Performance}

An overall mean score for reading accuracy, composed of the pseudo-words, context-free words and text reading mean scores was calculated. Figure 6 presents the differences in reading achievements between HG and LR group.

An Independent-sample t-test was carried out to assess the difference in reading accuracy between HG and LR group. Significantly, higher performance in overall reading accuracy was observed among HG group (t(204) $=5.61, p<0.001)$. Furthermore, HG group showed a significantly higher performance across the different reading accuracy measures: pseudo-words $(t(27.65)=3.09, p<0.01)$, context-free words $(t(27.57)=4.53, p<0.001)$ and text reading $(t(204)=5.57, p<0.001)$.

To compare the difference in reading rate, dependent-sample t-test was conducted. In Figure 7, reading rates in the different reading measures are presented. The HG group reading rates were significantly faster when compared to LR group in pseudo-words $(t(202)=-4.77, p<0.001)$ and context-free oral word naming $(t(202)=$ $-4.77, p<0.001)$ measures. In text reading measure, no significant difference in reading rate was found between HG $(M=163.58, \mathrm{SD}=109.20)$ and $\mathrm{LR}(M=161.52, S D=106.22)$.

Differences in reading comprehension were also assessed. An overall mean score was calculated (composed of the children's scores in "story recall" and "comprehension questions" measures of the read text). Independent-sample $t$ test points out significantly higher performance in HG group $(M=66.32, S D=20.08)$ when compared to LR group $(M=45.13, S D=22.27)$.

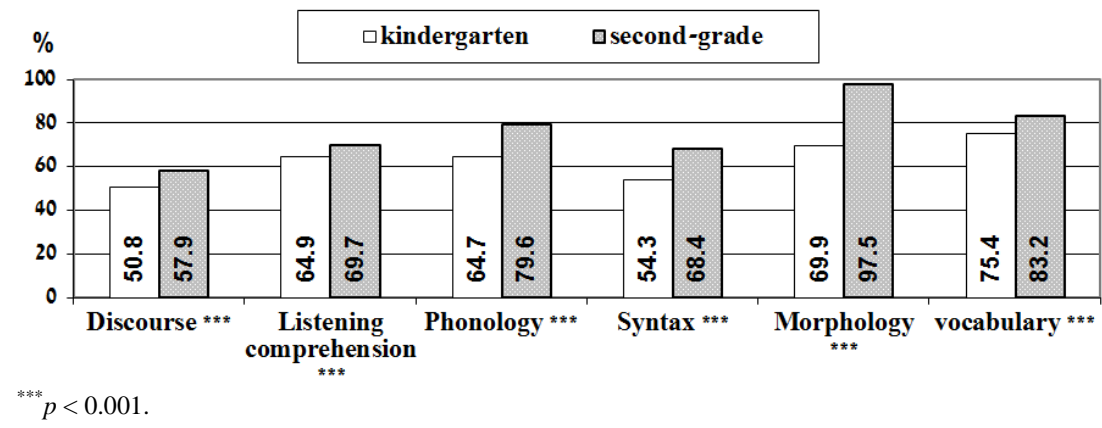

Figure 4. Progress in literacy knowledge among HG group after learning in the program.

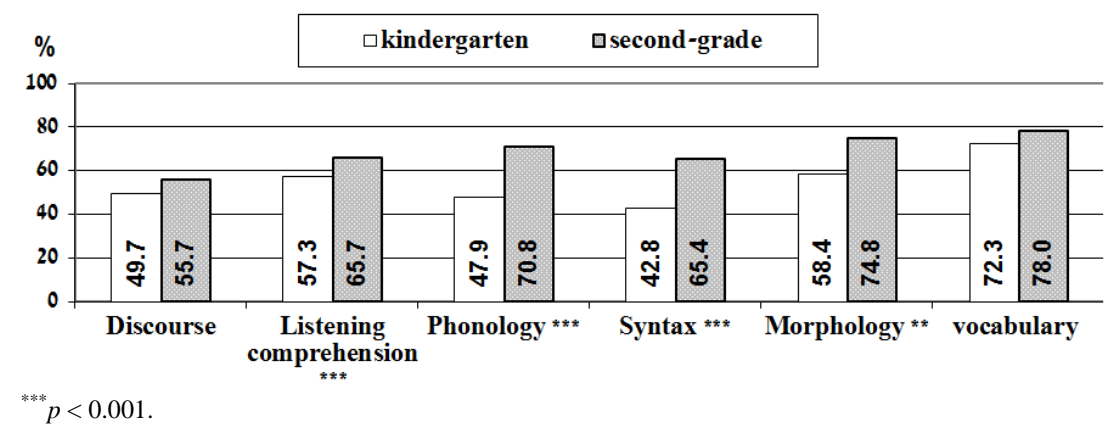

Figure 5. Progress in literacy knowledge among LR group after learning in the program. 


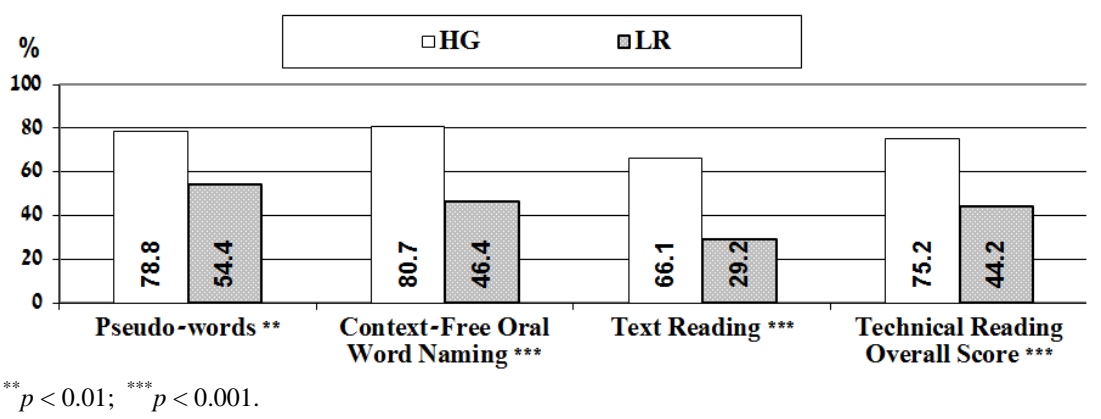

Figure 6. Differences in reading performance between the HG and LR group.

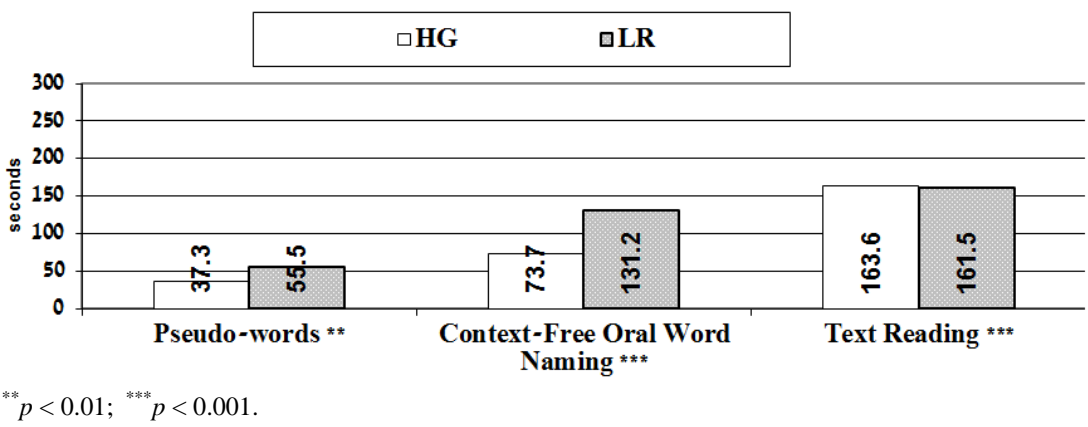

Figure 7. Differences in reading accuracy between the HG and LR group.

In order to estimate the conjoint effect of fostering the different literacy skills, a multiple linear regression analysis was conducted to evaluate the degree by which the different literacy measures predicted reading accuracy (decoding) and reading comprehension using stepwise interring method of the domains into the model (according to their contribution).

Table 3 presents the indices of the relative strength of each domain with relation to reading accuracy. In HG group, phonology and vocabulary accounted for $35 \%$ of the variance in reading accuracy $(F(2,178)=48.48, p<$ 0.001 ), while discourse, morphology, syntax and listening comprehension did not appear to add predictive strength beyond the former measures. In LR, syntax and vocabulary accounted for $53 \%$ of the variance of reading accuracy $(F(2,22)=12.25, p<0.001)$ while the other domains (discourse, phonology, morphology and listening comprehension) did not contribute to the explained variance.

From Table 4 we can conclude that amongst HG, listening comprehension, vocabulary and syntax explained $35 \%$ of the variance in reading comprehension $(F(3,177)=31.52, p<0.001)$, the other domains discourse, phonology and morphology did not add to the explained variance.

In LR group, reading comprehension was explained by phonology and syntax $(F(2,22)=11.09, p<0.001)$ they explained together $50 \%$ of the variance.

\subsection{Differences between Reading and Listening Comprehension}

In each group, a dependent-sample $\mathrm{t}$ test was conducted to compare between listening and reading comprehension skills. Significant difference was found in both HG $(t(180)=-2.91, p<0.01)$ and LR group $(t(24)=-5.80$, $p<0.001$ ) (see Figure 8).

\subsection{In Each Group, Differences between Reading and Listening Comprehension Were Found}

In the HG group, higher performance was noted in listening comprehension $(M=69.69, S D=13.75)$ compared to reading comprehension measure $(M=66.32, S D=20.08),(t(180)=-2.91, p<0.01)$. Similarly, in the LR group, better listening comprehension skills $(M=65.72, S D=11$.) were observed when compared to reading comprehension $(M=45.13, S D=22.27),(t(24)=-5.80, p<0.001)$.

Interestingly, on the story recall measure, significantly higher performance was obtained in the reading com- 
Table 3. Multiple regression analysis summary of reading accuracy at second grade by domains.

\begin{tabular}{|c|c|c|c|c|c|c|c|c|c|c|c|c|}
\hline Group & \multicolumn{6}{|c|}{ HG $(n=181)$} & \multicolumn{6}{|c|}{$\mathrm{LR}(\mathrm{n}=25)$} \\
\hline Domains & $\mathrm{r}$ & $r^{2}$ & $\Delta \mathrm{r} 2$ & $\mathrm{~B}(\mathrm{SE})$ & $\beta$ & $\mathrm{t}$ & $\mathrm{r}$ & $r^{2}$ & $\Delta \mathrm{r} 2$ & $\mathrm{~B}(\mathrm{SE})$ & $\beta$ & $\mathrm{t}$ \\
\hline Constant & & & & $-56.12(14.85)$ & & $-3.78 * * *$ & & & & $-131.03(50.30)$ & & $-2.61 *$ \\
\hline \multicolumn{13}{|l|}{ Discourse } \\
\hline Phonology & $0.53^{\mathrm{a}}$ & 0.28 & 0.27 & $0.69(0.13)$ & 0.37 & $5.40^{* * *}$ & & & & & & \\
\hline \multicolumn{13}{|l|}{ Morphology } \\
\hline Syntax & & & & & & & $0.65^{\mathrm{a}}$ & 0.43 & 0.42 & $1.59(0.72)$ & 0.37 & $2.20^{*}$ \\
\hline \multicolumn{13}{|c|}{ Listening comprehension } \\
\hline vocabulary & $0.59^{\mathrm{b}}$ & 0.35 & 0.08 & $0.92(0.20)$ & 0.32 & $4.85^{* * *}$ & $0.73^{\mathrm{b}}$ & 0.53 & 0.10 & $0.79(0.28)$ & 0.47 & $2.80 *$ \\
\hline $\mathrm{R}^{2}$ & & & & $35 \%$ & & & & & & $53 \%$ & & \\
\hline $\mathrm{F}$ & & & & $, 178)=48.48^{*}$ & & & & & & $22)=12.25^{* * *}$ & & \\
\hline
\end{tabular}

r-Multiple correlations; $\mathrm{r}^{2}-$ Percentage of explained variance; ${ }^{*} p<0.05 ;{ }^{* *} p<0.01 ;{ }^{* * *} p<0.001$.

Table 4. Multiple regression analysis summary of reading comprehension at second grade by domains.

\begin{tabular}{|c|c|c|c|c|c|c|c|c|c|c|c|c|}
\hline \multirow{2}{*}{$\begin{array}{c}\text { Group } \\
\text { Domains }\end{array}$} & \multicolumn{6}{|c|}{ HG $(n=181)$} & \multicolumn{6}{|c|}{$\mathrm{LR}(\mathrm{n}=25)$} \\
\hline & r & $r^{2}$ & $\Delta \mathrm{r} 2$ & $\mathrm{~B}(\mathrm{SE})$ & $\beta$ & $\mathrm{t}$ & $\mathrm{r}$ & $r^{2}$ & $\Delta \mathrm{r} 2$ & $\mathrm{~B}(\mathrm{SE})$ & $\beta$ & $\mathrm{t}$ \\
\hline Constant & & & & $-54.54(14.69)$ & & $-3.75^{* * *}$ & & & & $-55.84(28.14)$ & & -1.98 \\
\hline \multicolumn{13}{|l|}{ Discourse } \\
\hline Phonology & & & & & & & $0.63^{\mathrm{a}}$ & 0.40 & 0.40 & $0.98(0.45)$ & 0.39 & $2.16^{*}$ \\
\hline \multicolumn{13}{|l|}{ Morphology } \\
\hline Syntax & $0.59^{c}$ & 0.35 & 0.02 & $0.28(0.11)$ & 0.20 & $2.51^{*}$ & $0.71^{\mathrm{b}}$ & 0.50 & 0.10 & $0.52(0.25)$ & 0.38 & $2.10^{*}$ \\
\hline Listening comprehension & $0.51^{\mathrm{a}}$ & 0.26 & 0.26 & $0.51(0.13)$ & 0.29 & $3.82 * * *$ & & & & & & \\
\hline vocabulary & $0.57^{\mathrm{b}}$ & 0.33 & 0.07 & $0.69(0.20)$ & 0.24 & $3.41 * *$ & & & & & & \\
\hline $\mathrm{R}^{2}$ & & & & $35 \%$ & & & & & & $50 \%$ & & \\
\hline F & & & & $3,177)=31.52^{*}$ & & & & & $\mathrm{~F}(2$ & 22) $=11.09 * * *$ & & \\
\hline
\end{tabular}

Order of Entry to model: $\mathrm{a}=$ first, $\mathrm{b}=$ second, and so on. $\mathrm{r}-$ Multiple correlations; $\mathrm{r}^{2}$-Percentage of explained variance; ${ }^{*} p<0.05 ;{ }^{* *} p<0.01 ;{ }^{* * *} p<$ 0.001 .

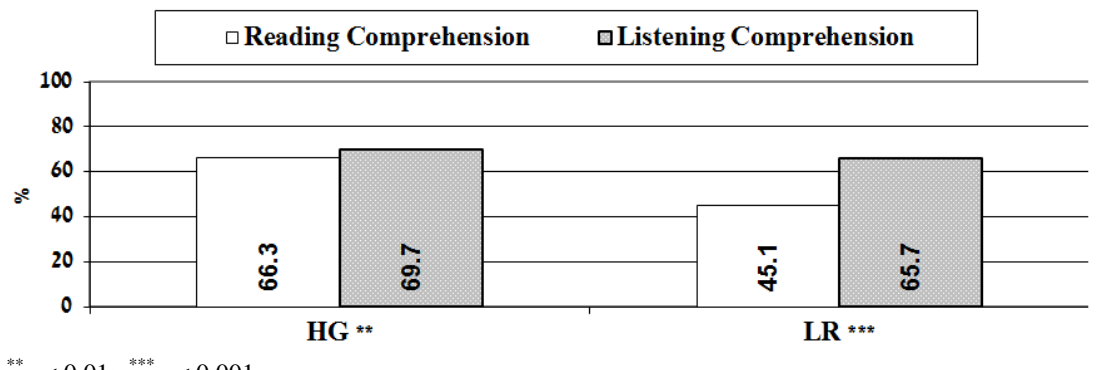

$\stackrel{* * *}{p}<0.01 ; \stackrel{* * *}{p} p<0.001$.

Figure 8. Differences in reading and listening comprehension within in each group.

prehension task when compared to listening comprehension, both in the LR and HG groups, $(t(180)=3.35, p<$ $0.01), t(24)=3.97, p<0.01)$, respectively. In contrast, in both groups, no significant difference in performance was observed in the listening comprehension questions when compared to reading comprehension questions. In 
the HG group, no significant difference was observed in their performance in the reading comprehension questions measure $(M=57.32, S D=24.23)$ and listening comprehension questions measure $(M=60.55, S D=22.30)$. Similarly, no difference in performance in the reading $(M=51.67, S D=26.57)$ and listening $(M=55.60, S D=$ 18.56) comprehension questions measures was found among the LR group.

\subsection{Reading Performance and Literacy Skills Correlations}

To assess the relationship between literacy skills and reading performance (after learning in the program), Pearson's correlation coefficients were computed for each group. In addition, the relationship between the different literacy domains was assessed (See Table 5).

Table 5. Pearson's correlation coefficients among literacy domains in HG and LR and Significant differences between correlations.

\begin{tabular}{|c|c|c|c|c|c|c|c|c|c|c|c|c|}
\hline & Group & $\mathrm{n}$ & & $\begin{array}{c}\text { Text } \\
\text { Reading }\end{array}$ & $\begin{array}{l}\text { Reading } \\
\text { omprehension }\end{array}$ & $\begin{array}{c}\text { Listening } \\
\text { comprehension }\end{array}$ & $\begin{array}{l}\text { Pseudo- } \\
\text { word } \\
\text { Reading }\end{array}$ & $\begin{array}{c}\text { Context- } \\
\text { Free Oral } \\
\text { Reading }\end{array}$ & Phonology & Morphology & Vocabulary & Syntax \\
\hline \multirow{4}{*}{ Text Reading } & HG & 181 & $\rho$ & & & & & & & & & \\
\hline & LR & 25 & $\rho$ & & & & & & & & & \\
\hline & & & $z$ & & & & & & & & & \\
\hline & HG & 181 & $\rho$ & $0.96 * *$ & & & & & & & & \\
\hline \multirow[t]{2}{*}{$\begin{array}{c}\text { Reading } \\
\text { comprehension }\end{array}$} & LR & 25 & $\rho$ & $0.97^{* *}$ & & & & & & & & \\
\hline & & & $z$ & -0.65 & & & & & & & & \\
\hline \multirow{3}{*}{$\begin{array}{l}\text { Listening } \\
\text { comprehension }\end{array}$} & HG & 181 & $\rho$ & $0.39 * *$ & $0.60^{* *}$ & & & & & & & \\
\hline & LR & 25 & $\rho$ & 0.28 & $0.46^{*}$ & & & & & & & \\
\hline & & & $z$ & 0.55 & 0.87 & & & & & & & \\
\hline \multirow{3}{*}{$\begin{array}{l}\text { Pseudo-word } \\
\text { Reading }\end{array}$} & HG & 181 & $\rho$ & $0.65^{* *}$ & $0.65 * *$ & $0.32 * *$ & & & & & & \\
\hline & LR & 5 & $\rho$ & $0.50 *$ & $0.59 * *$ & $0.54 * *$ & & & & & & \\
\hline & & & $z$ & 1.00 & 0.34 & -1.21 & & & & & & \\
\hline \multirow{3}{*}{$\begin{array}{l}\text { Context-Free } \\
\text { Oral Reading }\end{array}$} & HG & 181 & $\rho$ & $0.75^{* *}$ & $0.72 * *$ & $0.27 * *$ & $0.71^{* *}$ & & & & & \\
\hline & LR & 25 & $\rho$ & $0.58^{* *}$ & $0.59 * *$ & 0.34 & $0.73^{* *}$ & & & & & \\
\hline & & & $z$ & 1.37 & 1.21 & -0.34 & -0.18 & & & & & \\
\hline \multirow{3}{*}{ Phonology } & HG & 181 & $\rho$ & $0.50 * *$ & $0.55^{* *}$ & $0.45^{* *}$ & $0.43^{* *}$ & $0.47 * *$ & & & & \\
\hline & LR & 25 & $\rho$ & $0.59 * *$ & $0.64 * *$ & $0.50 *$ & $0.48^{*}$ & $0.46^{*}$ & & & & \\
\hline & & & $z$ & -0.57 & -0.62 & 0.29 & -0.28 & 0.06 & & & & \\
\hline \multirow{3}{*}{ Morphology } & HG & 181 & $\rho$ & $0.38^{* *}$ & $0.48^{* *}$ & $0.50 * *$ & $0.40^{* *}$ & $0.32 * *$ & $0.56^{* *}$ & & & \\
\hline & LR & 25 & $\rho$ & 0.39 & $0.49 *$ & $0.50 * *$ & $0.69^{* *}$ & 0.35 & 0.36 & & & \\
\hline & & & $z$ & -0.05 & -0.06 & 0 & -1.88 & -0.15 & 1.13 & & & \\
\hline \multirow{3}{*}{ Vocabulary } & HG & 181 & $\rho$ & $0.52^{* *}$ & $0.58 * *$ & $0.37 * *$ & $0.45^{* *}$ & $0.47^{* *}$ & $0.49 * *$ & $0.44 * *$ & & \\
\hline & LR & 25 & $\rho$ & $0.52^{* *}$ & $0.55^{* *}$ & 0.34 & $0.43^{*}$ & $0.63^{* *}$ & $0.42 *$ & $0.43^{*}$ & & \\
\hline & & & $z$ & 0 & 0.20 & 0.15 & 0.11 & -1.02 & 0.40 & 0.06 & & \\
\hline \multirow{3}{*}{ Syntax } & HG & 181 & $\rho$ & $0.37^{* *}$ & $0.49 * *$ & $0.51^{* *}$ & $0.44^{* *}$ & $0.35^{* *}$ & $0.56^{* *}$ & $0.69 * *$ & $0.46^{* *}$ & \\
\hline & LR & 25 & $\rho$ & $0.49 *$ & $0.56^{* *}$ & $0.51^{*}$ & $0.75^{* *}$ & $0.54 * *$ & $0.53^{* *}$ & $0.68^{* *}$ & $0.49 *$ & \\
\hline & & & $z$ & -0.65 & 0.43 & 0 & $-2.22 *$ & -1.05 & 0.19 & 0.08 & -0.17 & \\
\hline
\end{tabular}

${ }^{*} p<0.05 ;{ }^{* * *} p<0.01$. 
Table 5 points out moderate-strong positive correlations between all the assessed literacy skills and reading performance in HG group. Most prominently, the results point out a moderate correlation values between listening and reading comprehension ( $r=60, p<0.01)$, vocabulary and reading comprehension $(r=58, p<0.01)$, text reading measure and reading comprehension $(r=96, p<0.01)$ and to a strong positive correlation between pseudo-word reading and context-free oral word reading $(r=71, p<0.01)$.

In LR group, though weaker correlation values were found when compared to HG group, a similar pattern of results was observed. Moderate positive correlations were obtained between reading and listening comprehension and between vocabulary and reading comprehension, $(r=46, p<0.01),(r=55, p<0.01)$, respectively. A very strong positive correlation was found between text reading and reading comprehension $(r=0.97, p<0.01)$. In addition, a strong positive correlation was found between pseudo-word and context-free oral reading measures $(r=0.73, p<0.01)$.

In contrast, among LR, non-significant correlations were found between listening comprehension and text reading $(r=0.28)$, morphology and text reading $(r=0.39)$, context-free oral reading and listening comprehension $(r=0.34)$, vocabulary and listening comprehension $(r=0.34)$, morphology and context-free oral reading $(r$ $=0.35)$ and between morphology and phonology $(r=0.36)$.

Despite the small and non-persistent differences, similar correlations patterns were found between the two groups, but the differences in correlations were statistically non-significant. The correlations are similar across the literacy domains assessed in the current study independently from the belongingness to group (LR/HG), and show a similar pattern of learning, except between syntax and pseudo-words reading $(Z=-2.22, p<0.05)$, where stronger correlation was obtained in LR group $(\rho=0.75, p<0.01)$ when compared to HG group $(\rho=0.44$, $p<0.01$ ) This difference depends on the starting point between the two groups as explained in the discussion.

\section{Discussion}

In this study, we attempted to investigate the impact of literacy skills development on reading acquisition among at-risk Arabic speaking children. Consequently, the progress in the different literacy domains of the at-risk group (LR Group) was monitored and compared to their more advantageous counterparts (HG Group), following the implementation of interactive-balanced learning program for reading and writing acquisition. Literacy assessment was carried out on kindergarten end of year, prior to the program commencement and in second grade, after its termination. In addition, a post-test reading assessment was included to investigate the impact of literacy knowledge progress in reading skills.

The results of the present study indicate clear lag in the majority of the assessed literacy domains (phonology, morphology, syntax and listening comprehension) at kindergarten where the HG group demonstrated an initial superiority when compared to the LR group. The obtained results fall in line with previous findings addressing literacy development among at-risk children from low SES, stressing the necessity for early detection and intervention (e.g. Makhoul, 2006; Makhoul \& Ibrahim, 2012; Lundberg, Larsman, \& Strid, 2012).

In second grade, the post-test assessment pointed out the efficacy of "Arabic is our Language" program in promoting literacy skills and closing the gaps between the LR and HG groups, except in vocabulary knowledge. Despite the immense progress achieved in literacy skills, the LR group reading performance was lower than their peers, which, in part, may be attributed to their lower vocabulary knowledge. The DVC model-Decoding, Vocabulary and Comprehension (Perfetti, 2010) conceptualizes the reading skill in terms of the interplay between its cognitive and linguistic primary constituents: vocabulary (depth and width), decoding (including orthographic knowledge and phonology) and comprehension (ranging from basic sentence comprehension to more complex text representation that requires inference process). Though the three components are reciprocally interlinked, DVC model assumes that comprehension shares a direct connection solely with vocabulary, where word meaning mediates between decoding and comprehension, supplying feedback to the reader's efficacy in word identification. Accordingly, despite the progress that was made in literacy knowledge, intensive and successive intervention should be followed in order to compensate for the accumulated gaps resulting from the interplay of disadvantageous socio-economic background and impact of Arabic Diglossic context and orthographic features.

In addition, after participating in the program, HG has showed a great progress in literacy skills, which was also reflected on their reading skills, including comprehension. As previously suggested by Abu-Rabia (1999, 2000a, 2000b, 2003) and Makhoul (2006), the results indicate that multi-componential balanced literacy pro- 
moting program is required to compensate for the gaps in literacy skills as a result of Arabic the Diglossic nature and in overcoming its orthographic complexity. It's worthy to note that the program has demonstrated its efficacy despite the great variance in the children's literacy skills, thus stressing its adequacy as a reading acquisition program.

In order to shed light on the source of found discrepancy in reading skills between HG and LR group, we have investigated the children's performance, while taking into account both accuracy and speed components in the different reading measures pseudo-word, context-free word and text reading. The results points out higher ratio of reading errors among the LR group in all reading measures (See Figure 3). Comprehensive observation on the type of reading errors in the LR group revealed a wide spectrum of errors, in part resulting from the orthographic complexity of Arabic orthography (Hussein, 2014a) and the impact of the visual load as previously documented (Abdelhadi, Ibrahim, \& Eviatar, 2011; Hussein, 2014b; Taha, 2013). Many of these errors included phoneme omissions (short vowels represented by diacritical marks) and visually similar confusion in letters.

Multiple regression analysis showed that in HG group phonology and vocabulary explained 35\% of the variance in reading accuracy. Also in reading comprehension, listening comprehension, vocabulary and syntax predicted $35 \%$ of the variance. Within LR, 53\% of the variance of reading accuracy was explained by syntax and vocabulary, $50 \%$ of the variance of reading comprehension was explained by phonology and syntax.

In terms of reading rate, for the context-free word and pseudo-word reading measures, higher speed average was obtained in LR group in comparison to HG group, (See Figure 4), indicating a trade-off between speed and accuracy and to a lack of reading automaticity that hinders reading comprehension (e.g., Samuels, 2006). In the text reading measure, the similarity in the obtained reading speed average can be explained by the reciprocal nature of comprehension and decoding, where context facilitates word decoding. Indeed, according to the selfteaching hypothesis, contextual information plays a vital role in word decoding, especially when reading is less proficient (Share, 1995, 1999).

In addition to their hindered reading, when addressing the source of difficulties found in reading comprehension among LR group, the obtained pattern of results replicate previous finding linking it to listening comprehension skills. According to the simple view of reading comprehension, reading comprehension is the outcome of skillful decoding and listening comprehension (Gough \& Tunmer, 1986; Hoover \& Gough, 1990). Studies have shown that comprehension is reliant on language processing, requiring semantic processing, vocabulary and grammatical knowledge (e.g. Nation et al., 2004; Nation \& Snowling, 1998a, 1998b; Cain et al., 2001). Indeed, despite the progress made by the LR group after the termination of the learning program, significantly lower performance was yet found in listening comprehension when compared to the HG group, which also may account for their poor reading comprehension.

To establish the relationship between the different literacy measures and reading performance, Pearson's correlation coefficients were calculated, pointing to their interconnectedness and the correlations between the domains. Thus, these findings fall in the line with several former studies (see Adams, 1991; Perfetti, 2010; Rand Reading Study Group, 2002). The obtained results stress the multi-componential aspects of reading in Arabic, requiring a broader perspective, transcending phonology while considering other precursors of reading, such as morphological awareness (e.g. Mahfoudhi, Elbeheri, Al-Rashidi, \& Everatt, 2010; Makhoul \& Ibrahim, 2012; Mutlak, 2010). In the current study, positive significant correlation was found in the HG group between morphology and all reading measures with listening comprehension. In the LR group, positive significant correlations were obtained between morphology and reading comprehension, listening comprehension and pseudoword reading. Other relationships were also observed in both study groups such as, between syntactic knowledge and listening comprehension, listening comprehension, replicating a previous finding that pointed out the role of syntax in comprehension (e.g. Bentin, Deutsch, \& Liberman, 1990; Bowey, 1986a, 1986b; Perfetti, 2004). In both groups, pseudo-word and context-free oral reading highly correlated pointed out the dependency on decoding process in the first stages of reading (Al-Mannai \& Everatt, 2005; Saiegh-Haddad \& Geva, 2008; Taibah \& Haynes, 2011).

On the other hand, only modest correlations were obtained between the different literacy skills (phonology, morphology, vocabulary and syntax), reading measures (pseudo-words, free-context oral word and text reading) and comprehension measures (listening and reading comprehension) in LR group. Though significant progress has been made in literacy skills, following their participation in the program "Arabic is our Language”, the LR group has arrived with significantly lower literacy knowledge as a result of their deprived socio-economic context that adds up to the limitations induced by the Arabic Diglossic nature. Consequently, lower reading perfor- 
mance is still found when compared to HG group.

Contrary to reported contribution of morphological processes in Arabic reading, only a weak correlation between morphology and reading measures was found. Such finding might be explained by the superiority of phonological processes in the first stages of Arabic reading acquisition that gradually incorporates morphological knowledge as it builds up during schooling years. As a result, it would be beneficial to investigate the impact of the progress in morphological knowledge in predicting reading performance in later stages.

The non-significant differences in Pearson's correlations between HG and LR (except in pseudo-word reading and syntax) points out a similar relationship between the various domains, and suggests that the administrated learning program has been successful in bridging the gaps in literacy skills among LR group, observed since kindergarten.

To understand the significant difference in Pearson's correlation between HG and LR in syntax and pseudoword, we have to analyze the hidden relationships that underlie those two domains. Within LR, the correlation between those domains was stronger than the correlation in HG. The difference could be explained from two points of view.

The first, there was a difference in decoding and comprehension performances between LR and HG. For struggling readers as LR children, reading a new text or word is actually a pseudo-word reading because they have difficulties in decoding. Furthermore, in Arabic, one word could replace a whole sentence in English because of the high morphological density of Arabic. In this view, one word has its syntactic and morphological entity. As we know, decoding and comprehension correlate with syntax (Perfetti, Landi, \& Oakhill, 2004), and syntax is correlated with vocabulary (Huggins, 1977; Marchman \& Bates 1994; Tomasello, 2000) in which LR did not bridge the gaps in this domain with their counterparts in HG, and vocabulary is correlated to reading (Verhoeven \& Perfetti, 2011). LR children are trapped in a circle in which one disadvantage leads to another. Perfetti, Landi, \& Oakhill (2004) suggest that the role of syntax in reading may reflect differences in the development of functional language skills. The difference in the correlation in syntax and pseudo-word reading may point out differences in language skills.

The second, struggling readers rely on contextual cues to decode words and derive meaning. However, how LR group with low vocabulary could construct meaning? For them, decoding words is pseudo-word reading. LR group did not bridge the gaps in vocabulary and vocabulary correlates with syntax. Concerning DVC model (Perfetti, 2010), their performances both in decoding and comprehension were negatively affected. Efficient utilization of contextual cues in reading depends greatly on syntactic processing. While reading Arabic text, intervening factors add difficulties to the reading process; the reading rate slows besides performing reading errors, which are for the most part of a syntactic background (Ibrahim, Eviatar, \& Aharon-Peretz, 2007).

In conclusion, the results of the present study point out the contribution of "Arabic is our Language" as a multi-componential reading program, addressing both the cognitive precursors and developmental aspects intervening in reading acquisition (See Figure 2).

\section{Conclusion}

Fostering literacy knowledge amongst at-risk children is shown to be crucial in assisting them to close the gaps with their peers but is not sufficient for ensuring reading acquisition. Though progress was obtained in the LR group, the results stress the need for comprehensive, constructed and successive intervention in reading and writing acquisition that takes into account the challenges imposed on children as a result of the triad risk factors working on them: low literacy knowledge, the Diglossic nature of Arabic and its orthographic complexity and low SES background.

Thus, the key for ensuring a normal reading acquisition for these children is to learn in an interactive-balanced learning program for a prolonged period.

The contribution of the current learning program has also been successful in improving literacy skills among the children from more advantageous backgrounds, proving its adequacy to be implemented as a part of the Arabic language curriculum for the Arab sector.

Characteristics of the Arabic language bring difficulties and slow reading acquisition among native Arab children; findings teach us that with the right environment, taking into account the cognitive and developmental processes that underlie reading acquisition could bridge the complexities of the language characteristics and allow the learning process consistently and will benefit both among different students at-risk and among regular 
students.

With regard to the study implications for the scientific field, our results raise the necessity for constructing learning programs and developing early screening tools that are adapted to the characteristics of the Arabic language, taking into account the environmental and developmental aspects interacting and effecting normative literacy acquisition. Furthermore, in terms of pedagogical implications, our results emphasize the importance of developing and incorporating scientific-based learning materials in order to achieve optimal results when acquiring reading and writing. Ultimately, based on the collected data, our measures can be utilized as standardized assessment tools both by teachers and specialists in the field of learning disabilities and language pathologies.

It is worth noting that a follow up study will be conducted upon the students' commencement in fourth grade, after finishing their formal reading acquisition, to examine which of the assessed domains were more successful in predicting later reading performance.

\section{Acknowledgements}

The learning and instruction program "Arabic is Our Language” was developed in CET (The Center for Educational Technology) By the Arabic Section Staff in Literacy and Language Arts Department. CET sponsored the current study also.

Special thanks to the schools staff and the children for their collaboration and to the Chief Scientist of the Israeli Ministry of Education, which allowed us to get into the schools.

\section{References}

Abdelhadi, S., Ibrahim, R., \& Eviatar, Z. (2011). Perceptual Load in the Reading of Arabic: Effects of Orthographic Visual Complexity on Detection. Writing Systems Research, 3, 117-127. http://dx.doi.org/10.1093/wsr/wsr014

Abd El-Minem, I. M. (1987). Elm al-Sarf. Jerusalem: Al-Taufik Press [In Arabic].

Abu-Ahmed, H., M. A. (2008). Predictors of Early Reading Ability in Arabic: A Longitudinal Study from Kindergarten to Grade 2. University of Haifa, Faculty of Education, Department of Learning Disabilities.

Abu-Rabia, S. (1999). The Effect of Arabic Vowels on the Reading Comprehension of Second- and Sixth-Grade Native Arab Children. Journal of Psycholinguistic Research, 28, 93-101. http://dx.doi.org/10.1023/A:1023291620997

Abu-Rabia, S. (2000a). Effects of Exposure to Literary Arabic on Reading Comprehension in a Diglossic Situation. Reading and Writing: An Interdisciplinary Journal, 13, 147-157. http://dx.doi.org/10.1023/A:1008133701024

Abu-Rabia, S. (2000b). Dyslexia. Nazareth: Al-Nahda Publications [In Arabic]

Abu-Rabia, S., Share, D., \& Mansour, M. A. (2003). Word Recognition and Basic Cognitive Processes among ReadingDisabled and Normal Readers in Arabic. Reading and Writing, 16, 423-442. http://dx.doi.org/10.1023/A:1024237415143

Adams, M. J. (1991). Beginning to Read: Thinking and Learning about Print. Cambridge, MA: MIT.

Aikens, N. L., \& Barbarin, O. (2008). Socioeconomic Differences in Reading Trajectories: The Contribution of Family, Neighborhood, and School Contexts. Journal of Educational Psychology, 100, 235-251. http://dx.doi.org/10.1037/0022-0663.100.2.235

Al-Mannai, H. A., \& Everatt, J. (2005). Phonological Processing Skills as Predictors of Literacy amongst Arabic Speaking Bahraini School Children. Dyslexia, 11, 269-291. http://dx.doi.org/10.1002/dys.303

Ayari, S. (1996). Diglossia and Illiteracy in the Arab World 1. Language, Culture and Curriculum, 9, 243-253. http://dx.doi.org/10.1080/07908319609525233

Bentin, S., Deutsch, A., \& Liberman, I. Y. (1990). Syntactic Competence and Reading Ability in Children. Journal of Experimental Child Psychology, 49, 147-172. http://dx.doi.org/10.1016/0022-0965(90)90053-B

Bowey, J. A. (1986a). Syntactic Awareness and Verbal Performance from Preschool to Fifth Grade. Journal of Psycholinguistic Research, 15, 285-308. http://dx.doi.org/10.1007/BF01067676

Bowey, J. A. (1986b). Syntactic Awareness in Relation to Reading Skill and Ongoing Reading Comprehension Monitoring. Journal of Experimental Child Psychology, 41, 282-299. http://dx.doi.org/10.1016/0022-0965(86)90041-X

Cain, K., Oakhill, J. V., Barnes, M. A., \& Bryant, P. E. (2001). Comprehension Skill, Inference-Making Ability, and Their Relation to Knowledge. Memory \& Cognition, 29, 850-859. http://dx.doi.org/10.3758/BF03196414

Caravolas, M., Volın, J., \& Hulme, C. (2005). Phoneme Awareness Is a Key Component of Alphabetic Literacy Skills in Consistent and Inconsistent Orthographies: Evidence from Czech and English Children. Journal of Experimental Child Psychology, 92, 107-139. 
Castles, A., \& Coltheart, M. (2004). Is There a Causal Link from Phonological Awareness to Success in Learning to Read? Cognition, 91, 77-111 http://dx.doi.org/10.1016/S0010-0277(03)00164-1

Cohen, J. (1977). Statistical Power Analysis for the Behavioral Sciences. New Jersy: Lawrence Erlbaum Associates, Inc.

Cunningham, A. E., \& Stanovich, K. E. (1997). Early Reading Acquisition and Its Relation to Reading Experience and Ability 10 Years Later. Developmental Psychology, 33, 934-945. http://dx.doi.org/10.1037/0012-1649.33.6.934

Eviatar, Z., \& Ibrahim, R. (2001). Bilingual Is as Bilingual Does: Meta-Linguistic Abilities of Arabic-Speaking Children. Applied Psycholinguistics, 21, 451-471.

Eviatar, Z., Ibrahim, R., \& Ganayim, D. (2004). Orthography and the Hemispheres: Visual and Linguistic Aspects of Letter Processing. Neuropsychology, 18, 174-184. http://dx.doi.org/10.1037/0894-4105.18.1.174

Gough, P. B., \& Tunmer, W. E. (1986). Decoding, Reading, and Reading Disability. Remedial and Special Education, 7, 610. http://dx.doi.org/10.1177/074193258600700104

Hackman, D. A., Farah, M. J., \& Meaney, M. J. (2010).Socioeconomic Status and the Brain: Mechanistic Insights from Human and Animal Research. Nature Reviews Neuroscience, 11, 651-659. http://dx.doi.org/10.1038/nrn2897

Hanley, J. R. (2005). Learning to Read in Chinese. In M. J. Snowling, \& C. Hulme (Eds.), The Science of Reading: A Handbook (pp. 316-335).Oxford: Blackwell. http://dx.doi.org/10.1002/9780470757642.ch17

Hoover, W. A., \& Gough, P. B. (1990). The Simple View of Reading. Reading and Writing, 2, 127-160. http://dx.doi.org/10.1007/BF00401799

Huggins, A. W. F. (1977). Syntactic Aspects of Reading Comprehension. Cambridge, MA: Bolt Beranek and Newman.

Hussien, A. M. (2014a). Reading Arabic Shallow and Deep Genres in the Fifth and Tenth Grades: Indispensable Variables to Science of Reading. Journal of Education and Learning, 3, 60-69. http://dx.doi.org/10.5539/jel.v3n1p60

Hussien, A. M. (2014 b). The Indicating Factors of Oral Reading Fluency of Monolingual and Bilingual Children in Egypt. International Education Studies, 7, 75-90. http://dx.doi.org/10.5539/ies.v7n2p75

Khamis-Dakwar, R., \& Froud, K. (2007). Lexical Processing in Two Language Varieties: An Event Related Brain Potential Study of Arabic Native Speakers. In M. Mughazy (Ed.), Perspectives on Arabic Linguistics XX (pp.153-166). Amsterdam: John Benjamins. http://dx.doi.org/10.1075/cilt.290.13kha

Khamis-Dakwar, R., \& Makhoul, B. (2014). Meta-Linguistic Awareness Development and Its Implications for Language Learning Disability Assessment. In: E. Saiegh-Haddad, \& R. M. Joshi (Eds.), Handbook of Literacy in Arabic (pp. 279-300). Springer: The Netherlands. http://dx.doi.org/10.1007/978-94-017-8545-7_13

Ibrahim, R., Eviatar, Z., \& Aharon-Peretz, J. (2002). The Characteristics of the Arabic Orthography Slow Its Cognitive Processing. Neuropsychology, 16, 322-326. http://dx.doi.org/10.1037/0894-4105.16.3.322

Ibrahim, R., \& Aharon-Peretz, J. (2005). Is Literary Arabic a Second Language for Native Arab Speakers? Evidence from a Semantic Priming Study. The Journal of Psycholinguistic Research, 34, 51-70.

http://dx.doi.org/10.1007/s10936-005-3631-8

Ibrahim, R., Eviatar, Z., \& Aharon-Peretz, J. (2007). Meta-Linguistic Awareness and Reading Performance: A Cross Language Comparison. The Journal of Psycholinguistic Research, 36, 297-317. http://dx.doi.org/10.1007/s10936-006-9046-3

Ibrahim, R. (2009). The Cognitive Basis of Diglossia in Arabic: Evidence from a Repetition Priming Study within and between Languages. Psychology Research and Behavior Management, 12, 95-105.

Jednoróg, K., Altarelli, I., Monzalvo, K., Fluss, J., Dubois, J., Billard, C., \& Ramus, F. (2012). The Influence of Socioeconomic Status on Children's Brain Structure. PLOS ONE, 7, e42486. http://dx.doi.org/10.1371/journal.pone.0042486

LDAA-Learning Disabilities Association of Alberta (2009). Reading Readiness Screening Tool: Teacher Instructions (Draft 6.3). Alberta: LDAA.

Lonigan, C. J., Burgess, S. R., \& Anthony, J. L. (2000). Development of Emergent Literacy and Early Reading Skills in Preschool Children: Evidence from a Latent-Variable Longitudinal Study. Developmental Psychology, 36, 596-613. http://dx.doi.org/10.1037/0012-1649.36.5.596

Lundberg, I., Larsman, P., \& Strid, A. (2012). Development of Phonological Awareness during the Preschool Year: The Influence of Gender and Socio-Economic Status. Reading and Writing, 25, 305-320. http://dx.doi.org/10.1007/s11145-010-9269-4

Marchman. V., \& Bates, E. (1994). Continuity in Lexical and Morphological Development: A Test of the Critical Mass Hypothesis. Journal of Child Language, 21, 339-366. http://dx.doi.org/10.1017/S0305000900009302

Mahfoudhi, A., Everatt, J., \& Elbeheri, G. (2011). Introduction to the Special Issue on Literacy in Arabic. Reading and Writing: An Interdisciplinary Journal, 24, 1011-1018. http://dx.doi.org/10.1007/s11145-011-9306-y

Mahfoudhi, A., Elbeheri, G., Al-Rashidi, M., \& Everatt, J. (2010). The Role of Morphology Awareness in Reading Comprehension among Typical and Learning Disabled Native Arabic Speakers. Journal of Learning Disabilities, 43, 500-514. 
http://dx.doi.org/10.1177/0022219409355478

Makhoul, B. (2006). Investigating Arabic Reading Acquisition in a Constructed Tutoring Environment. Jerusalem: The Hebrew University of Jerusalem. (In Hebrew)

Makhoul, B., Eskandar, A., Ibrahim, G., \& Hijazy, M. (2010). Arabic Is Our Language for First Grade. Tel-Aviv: Center for Educational Technology (CET). (In Arabic)

Makhoul, B., \& Ibrahim, R. (2012). Investigating Arabic Reading Acquisition in 1st Grade Following the Interactive Model. Haifa: University of Haifa and Center for Educational Technology. (In Hebrew)

Makhoul, B., Olstein, E., \& Ibrahim, R. (2013). Investigating Reading and Writing Process in Arabic Considering the Interactive Model in 2nd-6th Grades: A Cross Sectional Study. Tel-Aviv: The Mofet Institute. (In Hebrew)

McBride-Chang, C., Wagner, R. K., Muse, A., Chow, B. W. Y., \& Shu, H. (2005). The Role of Morphological Awareness in Children's Vocabulary Acquisition in English. Applied Psycholinguistics, 26, 415-435. http://dx.doi.org/10.1017/S014271640505023X

Mohamed, W., Elbert, T., \& Landerl, K. (2011). The Development of Reading and Spelling Abilities in the First 3 Years of Learning Arabic. Reading and Writing, 24, 1043-1060. http://dx.doi.org/10.1007/s11145-010-9249-8

Morgan, P. L., Farkas, G., Hillemeier, M. M., \& Maczuga, S. (2009). Risk Factors for Learning-Related Behavior Problems at 24 Months of Age: Population-Based Estimates. Journal of Abnormal Child Psychology, 37, 401-413. http://dx.doi.org/10.1007/s10802-008-9279-8

Morgan, P. L., Farkas, G., Hillemeier, M. M., \& Maczuga, S. (2012). Are Minority Children Disproportionately Represented in Early Intervention and Early Childhood Special Education? Educational Researcher, 41, 339-351. http://dx.doi.org/10.3102/0013189X12459678

Mutlak-Abu Dahud, R. (2010). The Development of Morphological Abilities among Arab Children from 1st Grade to 10th Grade. Haifa: University of Haifa. (In Hebrew)

Nation, K., \& Snowling, M. J. (1998). Individual Differences in Contextual Facilitation: Evidence from Dyslexia and Poor Reading Comprehension. Child Development, 69, 996-1011. http://dx.doi.org/10.1111/j.1467-8624.1998.tb06157.x

Nation, K., \& Snowling, M. J. (1998b). Semantic Processing and the Development of Word-Recognition Skills: Evidence from Children with Reading Comprehension Difficulties. Journal of Memory and Language, 39, 85-101. http://dx.doi.org/10.1006/jmla.1998.2564

Nation, K., \& Snowling, M. J. (2004). Beyond Phonological Skills: Broader Language Skills Contribute to the Development of Reading. Journal of Research in Reading, 27, 342-356. http://dx.doi.org/10.1111/j.1467-9817.2004.00238.x

National Institute for Literacy (2008). Developing Early Literacy: Report of the Early Literacy Panel: A Scientific Synthesis of Early Literacy Development and Implications for Intervention. Jessup, MD: National Institute for Literacy.

Perfetti, C. A., \& Bolger, D. J. (2004). The Brain Might Read That Way. Scientific Studies of Reading, 8, $293-304$. http://dx.doi.org/10.1207/s1532799xssr0803_7

Perfetti, C. A., Landi, N., \& Oakhill, J. (2004). The Acquisition of Reading Comprehension Skill. In M. J. Snowling, \& C. Hulme (Eds.), The Science of Reading: A Handbook (pp. 227-247). Oxford: Blackwell.

Perfetti, C. (2010). Decoding, Vocabulary, and Comprehension. The Golden Triangle of Reading Skill. In M. G. McKeown, \& L. Kucan (Eds.), Bringing Reading Research to Life (pp. 291-302). New York: Guilford.

Pianta, R. C., \& Cox, M. J. (1999). The Transition to Kindergarten. A Series from the National Center for Early Development and Learning, York, PA: Paul H. Brookes Publishing Company, Maple Press Distribution Center.

Ramey, S. L., \& Ramey, C. T. (1999). The Transition to School for “At-Risk” Children. In R. C. Pianta, \& M. J. Cox (Eds.), The Transition to Kindergarten (pp. 217-251). Baltimore, MD: Paul H. Brookes.

RAND Reading Study Group (2002). Reading for Understanding, toward an R\&D Program in Reading Comprehension. Santa Monica, CA: RAND.

Rosenthal, R., \& Rosnow, R. L. (1984). Essentials of Behavioral Research: Methods and Data Analysis. New York: McGraw-Hill.

Saiegh-Haddad, E. (2008). On the Challenges That Diglossia Poses to the Acquisition of Basic Literacy Skills in Arabic. Literacy and Language, 1, 105-126. (In Hebrew).

Saiegh-Haddad, E. (2003). Linguistic Distance and Initial Reading Acquisition: The Case of Arabic Diglossia. Applied Psycholinguistics, 24, 431-451. http://dx.doi.org/10.1017/S0142716403000225

Saiegh-Haddad, E. (2004). The Impact of Phonemic and Lexical Distance on the Phonological Analysis of Words and Pseudo-Words in a Diglossic Context. Applied Psycholinguistics, 25, 495-512. http://dx.doi.org/10.1017/S0142716404001249

Saiegh-Haddad, E. (2005). Correlates of Reading Fluency in Arabic Diglossic and Orthographic Factors. Reading and Writing, 18, 559-582. http://dx.doi.org/10.1007/s11145-005-3180-4 
Saiegh-Haddad, E., \& Geva, E. (2008). Morphological Awareness, Phonological Awareness, and Reading in English-Arabic Bilingual Children. Reading and Writing: An Interdisciplinary Journal, 21, 481-504. http://dx.doi.org/10.1007/s11145-007-9074-x

Saiegh-Haddad, E. \& Henkin-Roitfarb, R. (2014). The Structure of Arabic Language and Orthography. In E. Saiegh-Haddad, \& M. Joshi (Eds.), Handbook of Arabic Literacy. Springer: The Netherlands.

Salami, N., Ibrahim, R. \& Shany, M. (Submitted). The Contribution of Presentation of Text in Spoken Arabic to Text Comprehension in Literary Arabic: A Developmental Study from 1st Grade to 6th Grade. (In Press)

Share, D. L. (1995). Phonological Recoding and Self-Teaching: Sine Qua Non of Reading Acquisition. Cognition, 55, 151121. http://dx.doi.org/10.1016/0010-0277(94)00645-2

Share, D. L. (1999). Phonological Recoding and Orthographic Learning: A Direct Test of the Self-Teaching Hypothesis. Journal of Experimental Child Psychology, 72, 95-129. http://dx.doi.org/10.1006/jecp.1998.2481

SISA-Simple Interactive Statistical Analysis (2013) Correlations. http://www.quantitativeskills.com/sisa/statistics/correl.htm

State of Israel Ministry of Education (2009). Arabic Language Curriculum: Language, Literature and Culture for Elementary School. http://meyda.education.gov.il/files/Tochniyot_Limudim/Arabic/ChinuchLeshoni.pdf

Taha, H. Y. (2013). Reading and Spelling in Arabic: Linguistic and Orthographic Complexity. Theory and Practice in Language Studies, 3, 721-727. http://dx.doi.org/10.4304/tpls.3.5.721-727

Taibah, N. J., \& Haynes, C. W. (2011). Contributions of Phonological Processing Skills to Reading Skills in Arabic Speaking Children. Reading and Writing, 24, 1019-1042. http://dx.doi.org/10.1007/s11145-010-9273-8

Tomasello, M. (2000). The Item-Based Nature of Children’s Early Syntactic Development. Trends in Cognitive Science, 4, 156-160. http://dx.doi.org/10.1016/S1364-6613(00)01462-5

Verhoeven, L., \& Perfetti, C. A. (2011). Introduction to This Special Issue: Vocabulary Growth and Reading Skill. Scientific Studies of Reading, 15, 1-7. http://dx.doi.org/10.1080/10888438.2011.536124

Ziegler, J. C., Bertrand, D., Tóth, D., Csépe, V., Reis, A., Faísca, L., \& Blomert, L. (2010). Orthographic Depth and Its Impact on Universal Predictors of Reading a Cross-Language Investigation. Psychological Science, 21, 551-559 http://dx.doi.org/10.1177/0956797610363406

Zuzovsky, R. (2010). The Impact of Socioeconomic versus Linguistic Factors on Achievement Gaps between Hebrew Speaking and Arabic-Speaking Students in Israel in Reading Literacy and in Mathematics and Science Achievements. Studies in Educational Evaluation, 36, 153-161. http://dx.doi.org/10.1016/j.stueduc.2011.02.004 
Scientific Research Publishing (SCIRP) is one of the largest Open Access journal publishers. It is currently publishing more than 200 open access, online, peer-reviewed journals covering a wide range of academic disciplines. SCIRP serves the worldwide academic communities and contributes to the progress and application of science with its publication.

Other selected journals from SCIRP are listed as below. Submit your manuscript to us via either submit@scirp.org or Online Submission Portal.
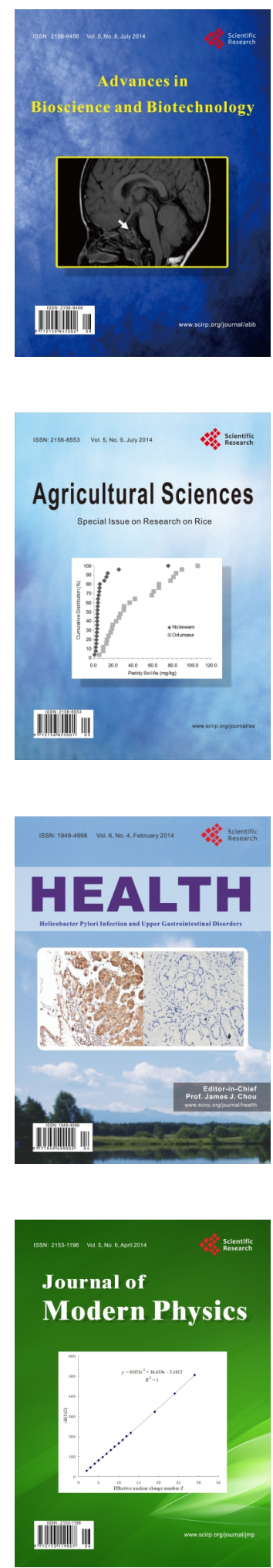
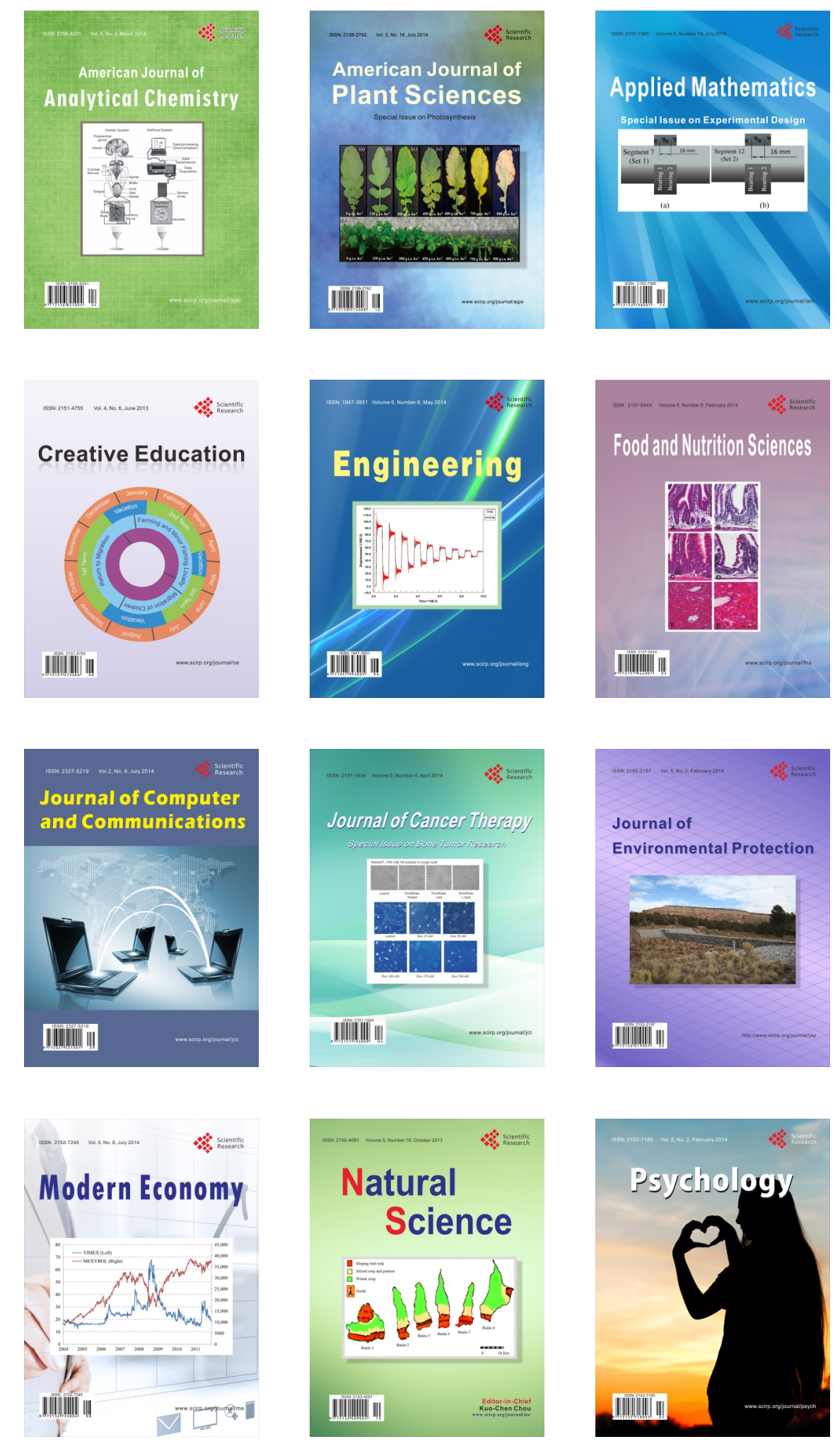